\title{
Parental Involvement as a Correlate of Academic Self-Efficacy of Secondary School Students
}

\author{
Dorothy Ebere Adimora, Charity Neejide Onyishi, Ucheaga Nonye Helen \\ Educational Psychology Unit, Department of Educational Foundations, Faculty of Education, University of Nigeria, Nsukka, Nigeria
}

\author{
Email address: \\ ebere.adimora@unn.edu.ng (D. E. Adimora)
}

\section{To cite this article:}

Dorothy Ebere Adimora, Charity Neejide Onyishi, Ucheaga Nonye Helen. Parental Involvement as a Correlate of Academic Self-Efficacy of Secondary School Students. International Journal of Secondary Education. Vol. 7, No. 3, 2019, pp. 69-76.

doi: $10.11648 /$ j.ijsedu.20190703.12

Received: June 27, 2019; Accepted: July 25, 2019; Published: August 12, 2019

\begin{abstract}
This study explored the correlation between parental involvement and academic self-efficacy of secondary school students in Nsukka education zone, Enugu state, Nigeria. Six types of parental involvement and two levels of academic selfefficacy were explored. Two research questions and two null hypotheses guided the study. The study was designed as a crosssectional correlational survey. From the population of 4,469 SSII student, a sample of 260 (122 male and 138 females) SSII students participated in the study. Academic self-efficacy scale (ASES) adapted and researcher-developed parental involvement scale (PIS) were used for data collection. The data was analyzed using Pearson's product moment correlation coefficient to answer research questions, while linear and multiple regression analysis were used to test the null hypotheses at 0.05 level of significance. The result of the analyses shows a positive moderate relationship between parental involvement on academic self-efficacy. It further reveals a positive moderate relationship between parental involvement and academic selfefficacy of male and female students. Based on the findings of the study, it was recommended among others that; there should be programs in educational institutions, to educate parents on the importance of applying the types of parental involvement in training their children.
\end{abstract}

Keywords: Academic Achievement, Parental Involvement, Parenting, Self-Efficacy

\section{Introduction}

People's believe in themselves; their ability and their strength are imperative in their professional level as well as in other situations and conditions necessary to accomplish a task or to achieve a set aim or goals. Success, especially in academic tasks requires consistent performance which heavily depends upon how people confidently deal with situations and changes coming forth in their life. Confidence is the pivot to success [1]. In behavioural sciences, confidence or believe in one's self is referred to as selfefficacy.

Self-efficacy does not mean how much a person likes oneself or how much one likes the task at hand; rather it means persons believe in their ability to reach a desired outcome in a designated area [2]. Bandura (1995) stated that self-efficacy creates a difference in how people feel, think, act, motivate themselves and behave. It provides the foundation for human motivation, well-being and personal accomplishment [3]. In education, self-efficacy is a key contributing factor to learners' success because it influences the choice learners make and the courses of action they pursue [4]. Bandura (1997) explained that students with high self-efficacy are more likely to achieve high academically than students with low self-efficacy [2]. This is because students with high self-efficacy work very hard to conquer a task and achieve high academic goals.

Academic self-efficacy refers to an individual's belief to successfully achieve a designated level on an academic task or attain a specific academic goal [5]. Bandura further stressed that academic self-efficacy reflects confidence in the ability to exert control over one's own motivation, behaviour, and social environment. Thus, academic self-efficacy means the individual belief and capacity through determination. McGrew (2008) views academic self-efficacy as individual belief in the ability to perform the necessary behaviour to produce a certain educational outcome [6]. This implies that academic self-efficacy is the belief to excel academically. 
According to Ormond (2008), academic self-efficacy refers to the belief that one can successfully engage in and complete course-specific academic tasks, such as accomplishing course aims, satisfactorily completing assignment, achieving a pass grade and meeting the requirement to continue to pursue one's major course of study [7].

Students with high academic self-efficacy resist failure through hard work, while students with low academic selfefficacy do not work hard but believe that they cannot do well, no matter how hard they try [8]. According to Shwarter and Hallum (2008), students with low academic self-efficacy attribute high academic achievement to good luck and failure to bad luck while students with high academic self-efficacy attribute high academic achievement to hard work and failure to laziness [9]. A high sense of self-efficacy increases students' readiness to invest efforts in their learning, serves them well to persist when facing difficulties and helps them to recover more quickly after a negative attainment. Conversely, a perceived sense of low self-efficacy diminishes students' interest in their learning, lessens from their capacity to resist when facing impediments and undermines their commitment to achieving their goals. A strong perceived sense of competence is likely to reduce the amount of stress students might experience in the course of their learning whereas a low self-estimation of capacity might result in high level of anxiety and agitation that often lead to irrational thinking that ultimately impair their cognitive and intellectual effectiveness. (Bandura, 1993) demonstrated that academic self-efficacy is a good predictor of academic achievement [10]. Kurumeh (2006) posited that students' achievement in senior school certificate examination has not been satisfactory [11]. This continued poor achievement by students has been a source of great concern to parents, teachers, and society.

Personal observation by the researchers of this study shows that in the area of this study, students seem to show low academic self-efficacy such as being easily discouraged in skills development, giving up easily, depression, difficulty with listening in class, being shy, easily angered, humiliation, laziness, not believing in one's self or ability and being unpredictable, being discouraged in academic activities, dropping out of school, low self-esteem, disruptive behaviors, and indiscipline. All these seem to account for students' low academic self-efficacy and invariably affect their academic achievement. If the students' sense of academic self-efficacy for doing a particular academic task is high, they are likely to set high goals. But if their sense of academic self-efficacy is low, they may avoid engagement in academic tasks or give up easily when problems arise.

Furthermore, some parents believe that providing their children with the basic requirements to achieve success in school would make their children do well in school [12]. Such parents tend to blame students' poor achievement on low self-efficacy. When parents are apparently concerned or involved in children's activities, it appears to energize the child's academic self-efficacy. In this study, parents may refer to guardian or caregivers and may not necessarily be the biological fathers or mothers of those children. The author further stressed that parents have a vital role to play in their children's upbringing and generally on human life; especially in the social, political, economic and educational aspects of human life.

Parent's interest and contribution in the education of their children have great influence on their children's academic self-efficacy. This goes with the opinion of Nokali, Bachman, and Votruba-Drzal, (2010) that the earlier a child's parental training begins, the more powerful the effects will be on the educational achievement of the child [13]. The types of parental involvement are more likely to affect the academic self-efficacy of student [14]. This fact makes it a duty for the parents to get involved in the education or upbringing of their children. Sigelman and Shaffer (2005) were of the view that parental involvement has effect on the academic self-efficacy of students. In this regard, the extent of parental involvement is such that the management and the welfare of the children is a duty of the parents [15].

According to Molly (2014), parental involvement is generally referred to as parents' participation in their children's education with the purpose of promoting their academic and social success [16]. On the other hand, Chowa, Masa, and Tucker (2013) posited that parental involvement may refer to parents responding to communication from teachers about their child's behavioral, attendance, or academic problems [17]. Epstein explained six types of parental involvement, which include parenting, communicating with families, volunteering, decision-making, learning at home and collaborating with the community.

Parenting refers to families creating home environments that support learning when schools provide them with information about such issues as children's health, nutrition, discipline, needs, and parenting approaches. Communicating with families bothers on how parents can play active role in children's academic activities when schools take adequate steps to ensure that parents are brought to the schools early in the academic year, before students develop problems, so that their first communication with them may be positive in nature and employment of variety of techniques for communicating with parents about their children's progress, decisions affecting their children, and school programs in general. Such as parent-teacher conferences, phone contact, report cards. Volunteering means getting parents actively involved in children's education as volunteers when schools enhance their connection to families by encouraging them to volunteer in school activities and attend school events. Volunteering efforts that tap parental talents enrich school programs and, particularly in upper grades, facilitate individualized learning [18]. Learning at home most parental participation in children's education occurs in the home. Schools must capitalize upon what parents are already doing by helping the children to assist and interact with their children at home learning activities that reinforce what is being taught in school. Schools should aim to increase parents' understanding of the curriculum and the skills their children need to develop at each stage in their schooling. 
Decision-making centers on involvement of parents in school governance, decision-making, and advocacy roles which is yet another strategy for fortifying links between schools and parents. Parent participates in decision-making when it is a comprehensive program involving learning support activities and those associated with improved student outcomes [18]. Collaborating with the community means that parents in conjunction with schools must draw regularly upon community resources to support efforts geared towards educating their children. Student outcomes seem to be greatest when families, schools, and community organizations and leaders work together. Thus, parental involvement could mean the situation in which parents are mindful of their children's educational affairs especially at school. In this case, they are charged with the responsibility to understand the educational needs of the student, communicate with the school and contribute to meeting the needs. Parental involvement is the active participation of parents on interest for the actualization of educational goals [18].

Parental involvement in their children's education with the purpose of promoting their academic and social success appears to be poor in the area of this study. Parental involvement in children's learning does not only affect learning outcomes but also influences learning motivation, academic self-efficacy, attention, task persistence, receptive vocabulary skills, and conduct problems in the classroom. This 'efficacy' factor brings the school curriculum goals within the situation at home. In this situation, parental involvement is such that involve management of the welfare of both male and female students. According to World Health
Organization (2017), gender refers to the socially constructed characteristics of women and men, such as norms, roles and relationships between groups of women and men [19]. Merriam (2016) believes that gender has a way of affecting students' academic self-efficacy. The researchers, therefore, seek to ascertain if gender has any role to play in academic self-efficacy of students in secondary schools in Nsukka Education Zone in Enugu State, Nigeria. This prompted the researchers' interest to carry out this study [20].

\section{The Present Study}

At present, there are no available study in the area of this study that has addressed the correlation between parental involvement and academic self-efficacy of secondary school students. Furthermore, researches conducted to date have tended to examine parental involvement in isolation. In the present study, we addressed this concern by investigating parental involvement as a correlate of academic self-efficacy of secondary school students. Specifically, the study ascertained the relationship among different types of parental involvement (parenting, communication, volunteering, learning at home, decision-making, and collaborating with community) on academic self-efficacy of secondary school students; and determined the relationship between parental involvement and academic self-efficacy of male and female secondary school students. The figure shows the relevance of the six types of parental involvement in a child's all-round development and their complementary roles in ensuring high academic self-efficacy of students. The relationship among these variables is shown in Figure 1.

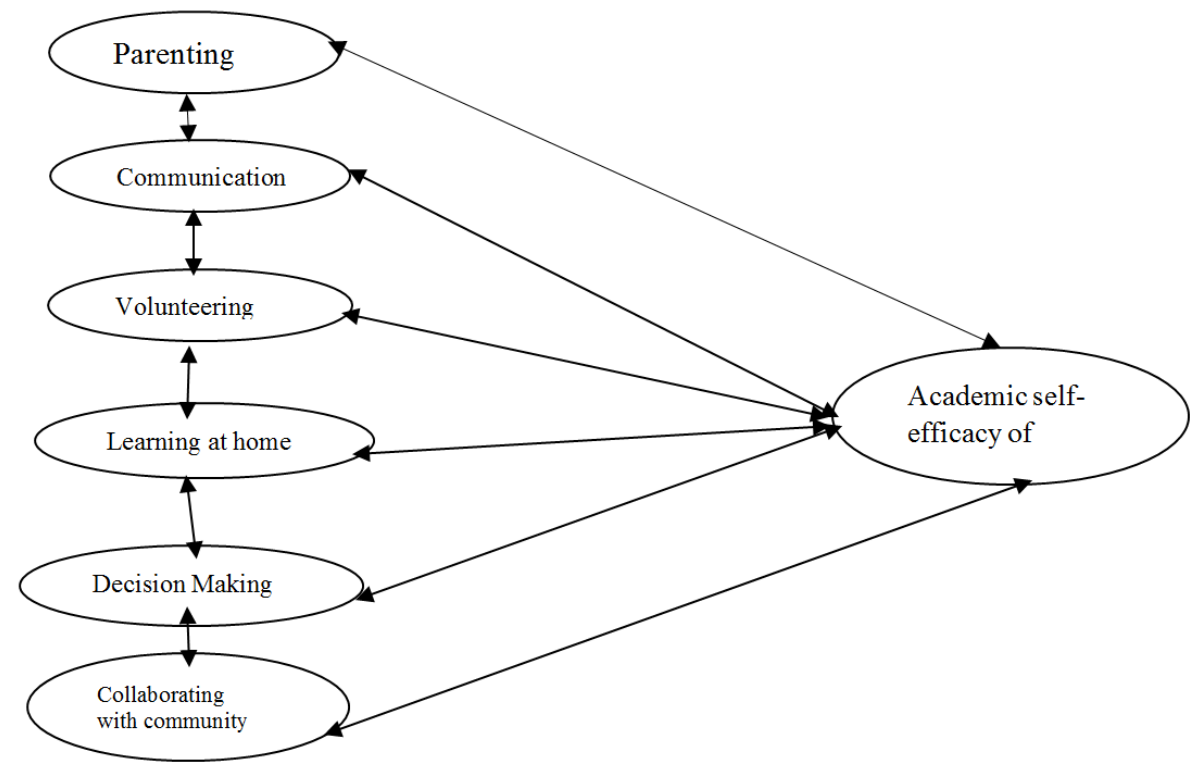

Figure 1. Model to examine the relationship among six types of parental involvement and their relationship with students' academic self-efficacy.

\section{Method}

\subsection{Participants}

Participants in the study were 4,469 SS II students in
Nsukka Education Zone of Enugu State, Nigeria. The sample consisted of 4,469 SSII students, a sample of 260 (122 males and 138 females) SSII student participants were used for this study. The data were collected by means of a questionnaire administered in school classes by research assistants. Prior to 
the data collection, the students were informed that the aim of the study was to explore their relationship with their parents and if they experience any academic challenge. They were also told that participation was voluntary. The parents were also informed about the data collection and given an opportunity to decide on their children's participation. The students did not write their names on questionnaire and the questionnaires were collected on-site by the research assistants to convince the students that they were anonymous. The questionnaire, the procedure and ethical considerations were approved by the University of Nigeria, Nsukka institutional review board (IRB). There are no conflicts of interests.

\subsection{Instruments}

The students' academic self-efficacy was measured with a 30 -item academic self-efficacy scale (ASES). The items were modified from [21]. The scales focused on academic selfefficacy of students [21]. Examples of items are: "I have a firm belief that I can do very well in academic tasks". "I am confident that I can deal effectively with my studies". "I can always manage to solve difficult academic problems if I try hard enough".

Responses were given on a 4-point scale from strongly agree (1) to strongly disagree (4). Cronbach's alpha for the scale was.89. Parental involvement was measured using a 36researcher developed scale (PIS) presented in six sub-clusters comprising the six types of parental involvement: parenting, communicating with families, volunteering, decision-making, learning at home and collaborating with the community. Examples of items are: "my parents encourage me to be resilient with my academic turbulences". "My parents pay my school fees on time" (parenting). "My parents visit my school to ascertain about my academic progress" (communication). "Parents offer huge resources support base for my school" (volunteering). My parents assist me to do my assignments" (Learning at home). My parents are involved in school policies concerning their children's academics" (decision making). Families draw community resources in educating their children" (collaborating). Responses were given on a 4-point scale from strongly agree (1) to strongly disagree (4). Cronbach's alpha for the six sub clusters were $.82, .78, .85, .81,87$, and 92 , respectively.

\subsection{Data Analysis}

Initially, the factorability of the 30 ASES items was examined. The Kaiser-Meyer- Olkin sampling adequacy was.89, above the recommended value of .6. Two main factors were extracted: high academic self-efficacy $(11.06 \%$ of variance); low academic self-efficacy $(32.05 \%$ of variance), which accounted for $43.11 \%$ of the variance. The factorability of the 36 PIS items was also examined, the Kaiser-Meyer-Olkin sampling adequacy was.92, above the recommended value of.6. Six main factors were extracted: parenting (21.03), communication (18.06), volunteering (23.08), learning at home (13.02), decision making (11.05), collaborating with community 08.01), which accounted for $94 \%$ of variance. The data were analyzed by means of Pearson's product moment correlation coefficient to answer the research questions. The decision rule was that correlation value ranging from 0.30 and below is low, above 0.30 to below 0.80 is moderate while from 0.80 and above is high. Linear and multiple regressions were used to test the null hypotheses at 0.05 level of significance.

Table 1. Pearson's product moment correlation analysis of the relationship between parental involvement (parenting, communication, volunteering, learning at home, decision making, collaborating with community) on academic self-efficacy of students.

\begin{tabular}{|c|c|c|c|c|c|c|c|c|c|c|}
\hline & \multicolumn{10}{|c|}{ Correlations } \\
\hline & $\mathbf{M}$ & SD & 1 & 2 & 3 & 4 & 5 & 6 & 7 & 8 \\
\hline Parenting & 3.45 & 53 & 1 & & & & & & & \\
\hline Communication & 3.27 & 63 & 571 & 1 & & & & & & \\
\hline Volunteering & 3.53 & 40 & 214 & 397 & 1 & & & & & \\
\hline Learning at home & 3.20 & 75 & 622 & 693 & 693 & 1 & & & & \\
\hline Decision making & 3.14 & 71 & 336 & 421 & 421 & 434 & 1 & & & \\
\hline Collaborating with community & 3.2 & 74 & 338 & 303 & 303 & 443 & 332 & 1 & & \\
\hline Academic self-efficacy & 3.08 & 34 & 26 & 542 & 542 & 340 & 209 & 223 & 435 & 1 \\
\hline
\end{tabular}

$00.0-0.30=$ low

$0.30-0.80=$ moderate

$0.80-$ Above $=$ high

The result presented indicates the respondents on parenting, communication, volunteering, learning at home, decision making, and collaborating with community correlated with academic self-efficacy of students. The result shows that the correlation coefficient (r) obtained between parenting and academic self-efficacy of students was 0.26 which indicated a positive low relationship between parenting and academic self-efficacy, the correlation coefficient (r) between communication and academic self-efficacy of students was 0.54 which indicated a positive moderate relationship between communication and academic self-efficacy of students. Volunteering correlated with academic self-efficacy was 0.54 which revealed a correlation coefficient (r) of a positive moderate relationship between volunteering and academic self-efficacy of students.

The correlation coefficient (r) obtained between learning at home and academic self-efficacy of students was 0.34 . This correlation coefficient (r) shows a positive moderate relationship between learning at home and academic selfefficacy of students. The correlation coefficient (r) obtained 
between decision making and academic self-efficacy of students was 0.20 . This correlation coefficient ( $r$ ) shows a positive low relationship between decision making and academic self-efficacy of students. The correlation coefficient (r) obtained between collaborating with community and academic self-efficacy of students was 0.22 . This shows a positive low relationship between collaborating with community and academic self-efficacy of students. Overall, there was a positive moderate relationship between parental involvements on academic self-efficacy of students.

Table 2. Regression of significance in the relationship between the types of parental involvement (parenting, communication, volunteering, learning at home, decision making, and collaborating with community) with academic self-efficacy.

\begin{tabular}{|c|c|c|c|c|c|c|}
\hline Model & & Sum of Squares & df & Mean Square & $\mathbf{f}$ & Sig \\
\hline \multirow{3}{*}{ Parenting } & Regression & 1.98 & 1 & 1.98 & 17.91 & 000 \\
\hline & Residual & 28.63 & 258 & 11 & & \\
\hline & Total & 30.62 & 259 & & & \\
\hline \multirow{3}{*}{ Communication } & Regression & 8.99 & 1 & 8.99 & 107.34 & 000 \\
\hline & Residual & 21.62 & 258 & 08 & & \\
\hline & Total & 30.62 & 259 & & & \\
\hline \multirow[t]{2}{*}{ Volunteering } & Residual & 26.88 & 258 & 104 & & \\
\hline & Total & 30.62 & 259 & & & \\
\hline \multirow{3}{*}{ Learning at home } & Regression & 3.54 & 1 & 3.54 & 33.7 & 000 \\
\hline & Residual & 27.07 & 258 & 105 & & \\
\hline & Total & 30.62 & 259 & & & \\
\hline \multirow[b]{2}{*}{ Decision making } & Regression & 1.33 & 1 & 1.33 & 11.79 & 001 \\
\hline & Residual & 29.28 & 258 & 114 & & \\
\hline \multirow{3}{*}{ Collaborating with community } & Regression & 1.52 & 1 & 1.52 & 13.55 & 000 \\
\hline & Residual & 29.09 & 258 & 113 & & \\
\hline & Total & 30.62 & 259 & & & \\
\hline \multirow{3}{*}{ Overall parental involvement } & Regression & 5.79 & 1 & 5.79 & 60.20 & 000 \\
\hline & Residual & 24.83 & 258 & 096 & & \\
\hline & Total & 30.62 & 259 & & & \\
\hline
\end{tabular}

Key: $\mathrm{df}=$ degree of freedom

Table 2 shows the result of the f- test on the relationship between the types of parental involvement which include parenting, communication, volunteering, learning at home, decision making, and collaborating with community, on academic self-efficacy. The $f$ - test on the relationship between parenting and academic self-efficacy of students indicating that there is a significance relationship between parenting and academic self-efficacy of students $f(258)$ $=17.91, \mathrm{p}=.000$. Therefore, the null hypothesis of no significant relationship between parenting and academic selfefficacy of students was rejected.

The f- test on the relationship between communication and academic self-efficacy of students indicating that there is a significant relationship between communication and academic self-efficacy of students $(258)=107.34, p=.000$. Therefore, the null hypothesis of no significant relationship between communication and academic self-efficacy of students was rejected.

The result of f-test on the relationship between volunteering and academic self-efficacy of students indicating that there is a significant relationship between volunteering and academic self-efficacy of students $\mathrm{f}$ (258) $=35.95, \mathrm{p}=000$. Therefore, the null hypothesis of no significant relationship between volunteering and academic self-efficacy of students was rejected.

The f-test on the relationship between learning at home and academic self-efficacy of students indicating that there is a significant relationship between learning at home and academic self-efficacy of students $\mathrm{f}(258)=33.79, \mathrm{p}=000$. Hence, the null hypothesis which stated that there is no significant relationship between learning at home and academic self-efficacy of students was rejected.

The f-test significance in the relationship between decision making and academic self-efficacy of students indicating that there is a significance relationship between decision making and academic self-efficacy of students $\mathrm{f}(258)=11.79$, $\mathrm{p}$ $=.001$. Hence, the null hypothesis which stated that there is no significant relationship between decision making and academic self-efficacy of students was rejected.

The $f$ - test significance in the relationship between collaborating with community and academic self-efficacy of students indicating that there is a significant relationship between collaborating with community and academic selfefficacy of students $\mathrm{f}(258)=13.55, \mathrm{p}=.000$. Therefore, the null hypothesis of no significant relationship between volunteering and academic self-efficacy of students was rejected, this reveals a significant relationship between collaborating with community and students' academic selfefficacy of students. Overall, there is a significant relationship between the types of parental involvement (parenting, communication, volunteering, learning at home, decision making, and collaborating with community), on academic self-efficacy of students. 
Table 3. Pearson's product moment correlation analysis of the relationship between parental involvement and academic self-efficacy of male and female students.

\begin{tabular}{lllllll}
\hline Gender & & \multicolumn{2}{c}{ Academic self-efficacy } & \multicolumn{2}{l}{ Parental involvement } & R \\
\hline & N & Mean & SD & Mean & SD & 075 \\
\hline Male & 138 & 3.07 & .368 & 3.23 & .475 & \\
Female & 122 & 3.12 & .313 & 3.39 & .425 & \\
\hline
\end{tabular}

Key: $\mathrm{N}=$ number of students, $\mathrm{SD}=$ standard deviation, $\mathrm{r}=$ correlation coefficient.

To answer research question 2, the analysis shows the scores from the responses of male and female respondents (students) on parental involvement correlated with their academic self-efficacy. The result shows that the male had academic self-efficacy mean score of 3.07 with standard deviation of.36 while the female students had academic selfefficacy mean score of 3.12 with standard deviation of.31. The result also shows the male mean score of 3.23 with standard deviation of.48 on parental involvement while the female students had a mean score of 3.39 with standard deviation of.42 on parental involvement. The correlation coefficient (r) obtained between parental involvement and academic self- efficacy of male and female students was.075. This correlation coefficient (r) shows a positive moderate relationship between parental involvement and academic self- efficacy of male and female students.

Table 4. Regression of significance in the relationship between parental involvement and academic self-efficacy of male and female secondary school students.

\begin{tabular}{lllllll}
\hline Model & & Sum of Squares & df & Mean Square & F & Sig \\
\hline \multirow{4}{*}{ Gender } & Regression & 174 & 1 & 174 & 1.47 & 226 \\
& Residual & 30.45 & 258 & 118 & & \\
& Total & 30.62 & 259 & & 18.13 & 000 \\
Parental involvement & Regression & 10.26 & 7 & 081 & & \\
& Residual & 20.36 & 252 & & \\
& Total & 30.62 & 259 & & & \\
\hline
\end{tabular}

Hypothesis 2 was tested using, f-test analysis to test for the significant relationship between parental involvement and academic self-efficacy of secondary school students based on gender. Table 4 shows the f- test significant relationship between parental involvement and academic self-efficacy of students indicating that there is a significant relationship between parental involvement and academic self-efficacy of secondary school students based on gender, f $(258)=1.47$, $\mathrm{p}=.000$. Therefore, the null hypothesis of no significant relationship between parental involvement and academic self-efficacy of secondary school students based on gender was rejected. Therefore, there is a significant relationship between parental involvement and academic self-efficacy of secondary school students based on gender.

\section{Discussion}

The result reveals the relationship among the different types of parental involvement (parenting, communication, volunteering, learning at home, decision making, collaborating with community) on academic self-efficacy of secondary school students. The findings show a positive low relationship between parenting and academic self-efficacy of students, a positive moderate relationship between communication and academic self-efficacy of students. The result also indicates a positive moderate relationship between volunteering and academic self-efficacy of students, a positive moderate relationship between learning at home and academic self-efficacy of students. It also shows a positive low relationship between decision making and academic self- efficacy of students, a positive low relationship between collaborating with community and academic self-efficacy of students. Overall, there was a positive moderate relationship between parental involvements on academic self-efficacy of students. The finding of this study is in line with Epstein (2005) which posited that there is a relationship with parental involvement and academic self-efficacy of secondary school students in Nsukka Education Zone such as parenting, learning at home, communicating with the families among others [18].

The findings of the study show a positive moderate relationship between parental involvement and academic self- efficacy of male and female students. The findings align with Crider, Goethals, Cavanaugh, and Solomon (2013) who assert that there is gender relationship between parental involvement and academic self-efficacy of students, that parents are simply unaware of the subtle influence they exert on sex-role development" [21].

\section{Conclusion}

Parental involvement on the welfare and academic activities of their children tremendously influences their children's proper development, intellectual development, academic self-efficacy and consequently boost their academic achievement.

\section{Implications of the Study}

The findings of this study have implication for parents, it 
gives the parents awareness on the significant role of their involvement in their child's learning activities in enhancing their child's learning ability and academic self- efficacy. The findings of this research have implication on educational institutions. The result helps in developing school programs associated with parental involvement in school activities, decisions and homework. Programs such as these can be implemented to bridge the gap between home and school while improving student's academic self-efficacy. On the other hand, the finding of this study has implication on teachers by providing them good insight on the co-operation needed between the school and the parents for the improvement of the self-efficacy of the students. Furthermore, the teachers assess the students' feelings, child's behavior and their relationship with their parents and assisting in identifying the measures which can be utilized to enhance parental involvement in the academic self-efficacy of their children. Finally, the study has implication on students, in helping to enhance their academic self-efficacy and learning outcome.

\section{Limitations of the Study}

Some of the respondents were not responsive and cooperative with the researcher to fill the questionnaire; they complained of having bulk of work to do and no time for filling the questionnaire. The respondents complained on the volume of the questionnaire and displayed noncommitment in responding to the questionnaire. However, amidst these turbulences, the findings of this study were not adversely affected.

\section{Recommendations}

Based on the findings of this study, it was recommended that: There should be programs in educational institutions, to educate parents on the importance of choosing appropriate parental involvement, while raising their children. The school administrators and teachers in their parent-teachers association (P. T. A) meetings should include, those factors which enables parents understand the need to boost their children's academic self-efficacy. Teachers should also lay emphasis in developing school programs such as open-dayconference between parent, teacher and students. There is need to let student and parents know that irrespective of their gender, they can still achieve positive behavioural outcomes if they make their own personal effort.

\section{References}

[1] Pintrich, P. R; Ronald W. M, \& Robert, A. B (2003). Beyond cold conceptual change: The role of motivational beliefs classroom contextual factors in the process of conceptual change. Review of Educational Research, 63 (2). http://journals.sagepub.com/doi/abs/10.3012/00346543063002 167.

[2] Bandura, A. (1977). Self-efficacy: Toward a unifying theory of behavior change. Psychological review, 84, 191-215.
[3] Bandura, A. (1995). Self-efficacy in changing societies. New York: Cambridge university press.

[4] Parajes, F. (2002). Self-efficacy beliefs in academic, settings. Review of education research. 66, 543.

[5] Bandura, A (1997) Self-efficacy: The exercise of control. New York: W. H. Free and Company.

[6] McGrew, K, S. (2008). Beyond IQ: Model of academic competence and motivation (MACM). https://www.slideshare.net/iapsych/macm-overview.

[7] Ormond, S (2008) Motivating learners in open and distance learning: do we need a new theory of learner support?', Open Learning: The Journal of Open and Distance Learning, 23: 3, 159-170 To link to this Article: DOI: 10 . 1080/02680510802419979.

[8] Pajare, F \& Schunk, D. H. (2001). Self-efficacy belief and school success: self-efficacy self- concept, and school achievement: In R. Riding \& S. Rayn. (eds. ). Perception. London Ablex publishing. http://www.des.emory.edu/mfp/pajaresschunk2001.html

[9] Schwarzer, R., \& Hallum, S. (2008). Perceived teacher selfefficacy as a predictor of job stress and burnout: Mediation analyses. Applied Psychology, 57 (1), 152-171. http://www.sciepub.com/reference/46233

[10] Bandura, A. (1993) Self-efficacy: Toward a unifying theory of behaviour change. Psychological review, 84, 191-215.

[11] Kurumeh, L. (2006). Social group of students and academic performance: Journal of Education. University of Calabar, June 2001.

[12] Adebayo, T. A. (2000). Comparative education. Ibadan: Oxford Press.

[13] Nokali. E. N, Bachman, H. J \& Votruba-Drzal, E. (2010). Parent involvement and children's academic and social development in elementary school. Journal of Child Development $\quad 81 \quad$ (3), 988-1005. https://www.ncbi.nlm.nih.gov/pmc/articles/PMC2973328/

[14] Afolabi, O. E. (2014). Parents' involvement and psychoeducational development of learners with special educational needs (SENs): An empirical review. Romanian Journal of School Psychology, 7 (14), 7-31. https://scholar.google.com/citations?user=YIoAs8AAAAAJ\& $\mathrm{hl}=\mathrm{en}$

[15] Sigelman, C. K. \& Shaffer, D. R. (1995). Developmental psychology: life span human development. Calif book/colenus.

[16] Molly, Z. (2014) Teachers' and parents' perceptions of parental involvement on Inner City children's academic success. Georgia Educational Research, 11 (1), 3. DOI: 10. 20429/ger. 2014.211010. https://pdfs.semanticscholar.org/730e/283242457fc5f99f8ffa2 $0 \mathrm{e} 4769 \mathrm{c} 4607908 \mathrm{c}$. pdf.

[17] Chows. Masa, R. \&Tucker, J. (2013). The effects of parental involvement on academic performance of Ghanaian youth: Testing measurement and relationship using structural equation modeling. Children and Youth Services Review, 35 (12), 2020-2030. doi: 10. 1016/j. childyouth. 2013. 09. 0. Retrieved https://csd.wustl.edu/publications/documents/wp1315.pdf.content/uploads/2009/10/ajc_v10n2_147-167.pdf. 
[18] Epstein, J. L. (2005). Perspectives and previews on research and policy for school, family and community partnerships. In Booth, A \& Dunn, J. (ed). Family-school links: how do they affect educational outcomes? Hillsdale, N, J. Erlbaum.

[19] World health organization, (2017). Concept of gender. http://www.gender.gov.nz/redgd.isr/umic_edu/gender

[20] Mirriam, W. (2016). Concept of gender. http://www.enm.wikipedia.org//gender
[21] Jinks, J., \& Morgan, V. "Children's perceived academic selfefficacy: An inventory scale, " The Clearing House, 72 (4), 1999, pp. 224-230

[22] Crider, Goethals, Cavanaugh \& Solomon. (2013). Gender differences in self-efficacy and academic performance among students of business administration. Journal of educational research, 39, 311-318. 